Laboratôrio de Fitopatologia, Universidade Estadual de Goiắs (UEG), Rodovia CO 330, Km 241, Anel Viărio, Setor Universitărio, CEP 75780-000 Ipameri, GO, Brasil

2Prédio de Controle Biológico, Embrapa Recursos Genéticos e Biotecnologia, Brasília, DF, Brasil

*autor correspondente $\boldsymbol{\nabla}$ gesianerib.guimaraes@gmail.com

\title{
Ação de metabólitos voláteis e não voláteis de Trichoderma harzianum sobre o crescimento de Cladosporium herbarum
}

\author{
Action of volatile and non-volatile metabolites of Trichoderma \\ harzianum on the growth of Cladosporium herbarum
}

Gesiane Ribeiro Guimarães ${ }^{1 *}$, Deziany da Silva Ferreira' ${ }^{1}$, Carolina dos Santos Galvão'

Sueli Corrêa Marques Mello², Daniel Diego Costa Carvalho'

RESUMO: O objetivo deste trabalho foi avaliar o crescimento de cinco isolados de Trichoderma harzianum em diferentes temperaturas e, em seguida, o efeito de seus metabólitos voláteis e não voláteis na inibição do crescimento de Cladosporium herbarum na melhor temperatura de crescimento constatada para os antagonistas. Para tanto, o crescimento micelial dos antagonistas foi avaliado ao longo de sete dias, nas temperaturas de $10,25,30$ e $40^{\circ} \mathrm{C}$, sob fotoperíodo de $12 \mathrm{~h}$. Em seguida, os antagonistas tiveram seus metabólitos avaliados quanto à inibição do crescimento de C. herbarum em ensaios com metabólitos voláteis e não voláteis termoestáveis a $25^{\circ} \mathrm{C}$. Não houve diferença entre a taxa de crescimento dos isolados, quando estes foram submetidos a uma mesma temperatura. Além disso, verificou-se que o melhor crescimento de $T$. harzianum ocorreu a $25^{\circ} \mathrm{C}$. Quanto à produção de metabólitos voláteis tóxicos ao patógeno, o isolado CEN288 inibiu em 59\% o crescimento de $C$. herbarum, enquanto que para metabólitos não voláteis termoestáveis, todos os isolados foram similares entre si, inibindo entre 29 e $40 \%$ o crescimento do patógeno a $25^{\circ} \mathrm{C}$.

PALAVRAS-CHAVE: Phaseolus vulgaris, controle biológico, fisiologia de fungos.
ABSTRACT: The objective of this study was to evaluate the growth of five isolates of Trichoderma harzianum under different temperatures and, just after, the effect of its volatile and non-volatile metabolites on the inhibition of the growth of Cladosporium herbarum in the best temperature of growth verified for the antagonists. For this purpose, the mycelial growth of the antagonists was assessed over 7 days, at temperatures of $10,25,30$ and $40^{\circ} \mathrm{C}$, under $12 \mathrm{~h}$ photoperiod. Then, the antagonists had its metabolites evaluated as to inhibition of the growth of C. herbarum in assays using volatile and non-volatile thermostable metabolites at $25^{\circ} \mathrm{C}$. There were not differences among the isolates growth rate, when these were submitted to the same temperature. Besides, it was found that the better growth of T. harzianum occurred at $25^{\circ} \mathrm{C}$. As to production of volatile metabolites toxic to the pathogen, CEN288 inhibited $59 \%$ of the C. herbarum growth, while for non-volatile thermostable metabolites, all isolates were similar, inhibiting between 29 and $40 \%$ the pathogen growth at $25^{\circ} \mathrm{C}$.

KEYWORDS: Phaseolus vulgaris, biological control, fungi physiology.

\section{Introdução}

A maioria das culturas destinadas à produção de alimentos está sujeita ao ataque de doenças, cujos agentes etiológicos em grande parte são transmitidos pelas sementes (CORRÊA et al., 2008). No caso específico do feijoeiro, mais de $50 \%$ das enfermidades são transmitidas via sementes (MARINO; MESQUITA, 2009). A incidência de patógenos em sementes de feijoeiro, tais 
como o fungo Cladosporium herbarum, provoca podridões e irregularidades na germinação, bem como no estabelecimento do estande inicial da cultura (CARVALHO et al., 2011).

Carvalho et al. (2014) preconizam o tratamento de sementes com agentes biológicos em substituição aos químicos, com vantagens, especialmente do ponto de vista sócio-ambiental. O controle biológico é conhecido a cerca de 70 anos (POMELLA; RIBEIRO, 2009). O fungo Trichoderma (reino Fungi, filo Ascomycota, classe Pyrenomycetes, ordem Hypocreales) foi relatado como eficiente em controlar patógenos que ocasionam tombamento, tais como espécies de Fusarium e Rhizoctonia, como foi demonstrado por Ahmad e Baker (1987) e Baker e Snyder (1965). Estes trabalhos ofereceram o embasamento técnico para dezenas de produtos comerciais à base de Trichoderma no mercado mundial (POMELLA; RIBEIRO, 2009).

Fundamentalmente, os fungos do gênero Trichoderma revestem-se de interesse para pesquisa em controle biológico por serem, em grande parte, exímios produtores de antibióticos e enzimas degradadoras de parede celular de outros fungos e pela facilidade com que colonizam os diversos substratos, inclusive raízes de plantas (MACHADO et al., 2012).

Seus vários mecanismos, atuando individualmente ou em conjunto, podem induzir efeitos supressivos sobre as doenças vegetais (HARMAN et al., 2004). Por exemplo, a produção de metabólitos secundários capazes de inibir o crescimento e/ou a germinação de esporos do fitopatógeno alvo (antibiose). Tais substâncias, de baixo peso molecular e com atividade antimicrobiana, podem ser voláteis ou não voláteis (CARVALHO et al., 2014). Dentre essas, citam-se: alquilpironas, isonitrilas, policetídeos, peptabólitos, dicetopiperazinas, sesquiterpenos e esteróides. O modo de ação desses metabólitos com atividade antibiótica é na maioria das vezes desconhecido, haja vista a escassez de informações relativas ao papel dessas substâncias, obtidas a partir de bioensaios, tanto in vitro como in vivo, sendo gliovirina, gliotoxina e peptabólitos como as tricorzianinas os mais estudados (EL-HASAN et al., 2009).

Outro aspecto relevante para o controle biológico reside na temperatura mais apropriada para o crescimento in vitro de Trichoderma, com vistas a auxiliar nas metodologias propostas para testes em condições controladas (ALWATHNANI et al., 2012). Em decorrência, o objetivo deste trabalho foi avaliar o crescimento de cinco isolados de Trichoderma harzianum em diferentes temperaturas e, em seguida, o efeito de seus metabólitos voláteis e não voláteis na inibição do crescimento de C. herbarum na melhor temperatura de crescimento constatada para os antagonistas.

\section{Material e Métodos}

\section{Isolados de antagonistas e patógeno}

Os isolados de T. harzinaum (CEN287, CEN288, CEN289, CEN290 e CEN316) pertencem à Coleção de Fungos para Controle Biológico de Fitopatógenos e Plantas Daninhas da Embrapa (CARVALHO et al., 2015). O isolado de C. herbarum (UEG0812) pertence a micoteca da Universidade Estadual de Goiás (UEG) e foi obtido a partir de amostras de sementes de feijoeiro 'Pérola' provenientes de áreas experimentais da

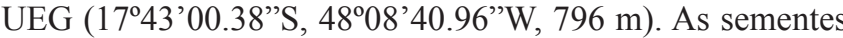
estavam infectadas pelo patógeno, o qual foi identificado conforme Ellis (1971).

\section{Crescimento de Trichoderma harzianum a diferentes temperaturas}

Discos de ágar $(5 \mathrm{~mm})$ contendo micélio dos antagonistas foram, individualmente, depositados no centro de placas de Petri contendo meio BDA. Após o desenvolvimento das colônias, o crescimento radial do micélio foi estimado aos sete dias de incubação nas temperaturas de $10,25,30,40^{\circ} \mathrm{C}$. Os dados do crescimento dos fungos em cada temperatura foram transformados em porcentagem. Este ensaio foi conduzido duas vezes com cinco repetições para cada isolado de T. harzinaum.

\section{Metabólitos voláteis}

Bases das placas contendo o antagonista e o patógeno foram sobrepostas e unidas com filme plástico transparente. As placas foram incubadas a $25^{\circ} \mathrm{C}$ e fotoperíodo de $12 \mathrm{~h}$, de forma que as bases superiores fossem aquelas que continham o patógeno. Após sete dias, quando a colônia testemunha (patógeno sem antagonista) encontrava-se totalmente colonizada, tomaram-se as medidas de diâmetro das colônias de C. herbarum. Para obtenção das médias de crescimento do patógeno, considerou-se como $100 \%$ de crescimento, a área final ocupada pela testemunha (CARVALHO et al., 2014).

\section{Metabólitos não voláteis termoestáveis}

Cinco discos $(5 \mathrm{~mm})$ de ágar retirados das margens de culturas de $T$. harzianum foram transferidos para frascos Erlenmeyer $(500 \mathrm{~mL})$, contendo $250 \mathrm{~mL}$ de meio Batata-Dextrose (BD). Após seis dias de cultivo sob agitação (Incubadora Kline modelo: Q225K) a $120 \mathrm{rpm}$ e temperatura de $25^{\circ} \mathrm{C}$, as culturas foram filtradas em gaze esterilizada e posteriormente autoclavadas a $120^{\circ} \mathrm{C}$ durante $20 \mathrm{~min}$. Em seguida, cinco mililitros do filtrado de cada isolado foi acrescentado a $15 \mathrm{~mL}$ de BDA fundente (ágar a 28\%), nas placas de Petri. Após solidificação do meio, um disco de ágar (5 mm), contendo micélio do patógeno, foi depositado sobre a superfície do meio. A testemunha consistiu na adição de $5 \mathrm{~mL}$ de água destilada esterilizada (ADE) ao BDA fundente. As placas foram incubadas a $25^{\circ} \mathrm{C}$ e fotoperíodo de $12 \mathrm{~h}$, até completa colonização do meio pelo patógeno nas placas testemunhas. Tomaram-se, então, as medidas de diâmetros das colônias do patógeno, ao sétimo dia, as quais foram convertidas em percentagem conforme o item anterior (CARVALHO et al., 2014). Os experimentos com metabólitos voláteis e não voláteis termoestáveis foram conduzidos duas vezes, em delineamento inteiramente ao acaso (DIC), com quatro repetições para cada isolado de T. harzianum.

\section{Análises estatísticas}

Os dados referentes aos experimentos com metabólitos voláteis e não voláteis termoestáveis foram submetidos à análise de variância ao teste de Scott-Knott $(\mathrm{P} \leq 0,05)$. Realizaram-se, também, análises de regressão para o percentual de colonização das placas submetidas a diferentes temperaturas. As análises 
foram realizadas no programa estatístico SISVAR 5.3 (FERREIRA, 2011).

\section{Resultados e Discussão}

A taxa de crescimento dos isolados de T. harzianum não variou significativamente em cada temperatura avaliada: $10^{\circ} \mathrm{C}$ (14,29 a $16,28 \%$ de colonização); $25^{\circ} \mathrm{C}(99,71$ a $100 \%) ; 30^{\circ} \mathrm{C}$ $(75,71$ a $82,85 \%)$ e $40^{\circ} \mathrm{C}(18,42$ a $25,57 \%)$ (Figura 1$)$. Em geral, o crescimento dos isolados pôde ser representado por um modelo polinomial do segundo grau, significativo e com alto coeficiente de determinação $\left(y=-0,3513 x^{2}+17,6130 x-124,9368\right.$; $\left.\mathrm{R}^{2}=0,9937 ; \mathrm{P} \leq 0,01\right)$. O melhor crescimento de T. harzianum ocorreu a $25^{\circ} \mathrm{C}$, que foi a temperatura adotada para os testes com metabólitos voláteis e não voláteis termoestáveis.

Quanto à produção de metabólitos voláteis, o isolado CEN288 foi o que exibiu melhor ação antifúngica, pois inibiu em $59 \%$ o crescimento do patógeno, sendo estatisticamente superior aos demais (Tabela 1). Os outros isolados foram superiores à testemunha, apresentando valores médios de porcentagem de inibição que variaram entre 6,65 e 32,72\%. Já no experimento para verificação do efeito de metabólitos não voláteis termoestáveis, todos os isolados foram similares entre si, sendo superiores à testemunha. $\mathrm{O}$ percentual médio de inibição por metabólitos não voláteis termoestáveis variou entre 28,67 e $40,14 \%$.

No presente estudo, atenção inicial foi dirigida à temperatura como fator essencial para a capacidade de manipular o crescimento de um microrganismo (WOO et al., 2006). Neste sentido, após verificar que a temperatura de $25^{\circ} \mathrm{C}$ foi a melhor para o crescimento dos isolados de T. harzianum, os testes subsequentes com metabólitos foram realizados $25^{\circ} \mathrm{C}$. Em concordância com os resultados da Figura 1, Hajieghrari et al. (2008) consideram que a temperatura ótima para crescimento micelial não difere entre isolados de uma mesma espécie de Trichoderma, embora a maioria destes sejam considerados mesófilos. De forma análoga, Auler et al. (2013) verificaram que o antagonismo de $T$. harzinaum contra Sclerotium rolfssi diminuiu com o aumento da temperatura de $22^{\circ} \mathrm{C}$ para $28^{\circ} \mathrm{C}$ em testes de cultura pareada, condição esta em que a capacidade de crescimento micelial do antagonista para a rápida colonização do meio

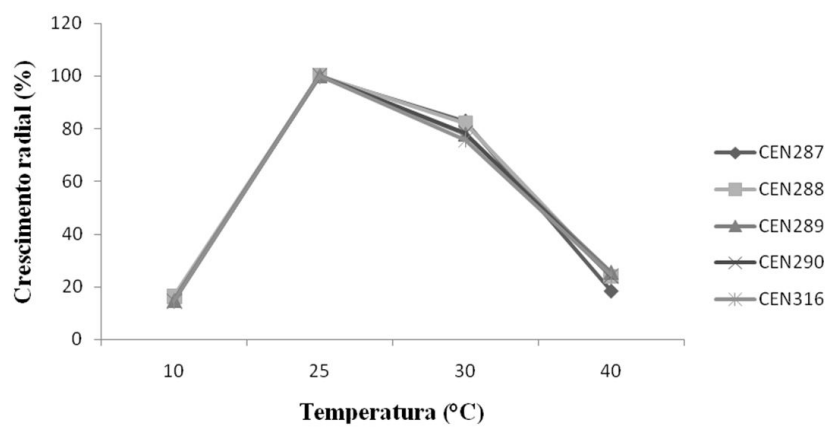

Figura 1. Efeito da temperatura sobre o crescimento micelial de Trichoderma harzianum. Cada valor médio provém de dois experimentos com cinco repetições para cada isolado. Modelo polinomial para os isolados: $\mathrm{y}=-0,3513 \mathrm{x}^{2}+17,6130 \mathrm{x}-124,9368\left(\mathrm{R}^{2}=0,9937 ; \mathrm{P} \leq 0,01\right)$. é fundamental. Alwathnani et al. (2012) também obtiveram incremento no crescimento micelial de Trichoderma viride $\mathrm{e}$ T. harzianum de $100 \%$, apenas manipulando a temperatura, a qual foi mantida a $25^{\circ} \mathrm{C}$.

Baseando-se nos resultados da Tabela 1, apenas o isolado CEN288 se destacou quanto a produção de metabólitos voláteis, com valores médios de inibição superiores a 50\%, semelhantemente aos verificados por Lopes et al. (2012). A alta produção de antibióticos não voláteis não foi correlacionada à alta produção de inibidores voláteis. Esses metabólitos produzidos por T. harzianum desempenham papel importante na surpressão do crescimento micelial do patógeno, dado que ambos os fungos compartilhariam a mesma câmara de crescimento. Sendo assim, tal evento puramente fungistático, seria determinante no controle da doença disseminada por sementes (AGÜERO et al., 2008) e também no caso daquelas causadas por patógenos habitantes do solo (DE BOER et al., 2003). Uma possível explicação para CEN288 ter se destacado dos demais quanto à produção de metabólitos voláteis reside no fato de que os mecanismos de ação, tais como produção de metabólitos voláteis tóxicos, podem variar entre isolados da mesma espécie (CARVALHO et al., 2014).

Conforme postulam Demirci et al. (2011), muitos fatores devem ser analisados para escolha de um isolado visando sua aplicação a campo. Nesse aspecto, os testes de produção de metabólitos não voláteis termoestáveis permitem inferir sobre a termoestabilidade de tais metabólitos frente a altas temperaturas do solo em regiões tropicais. De acordo com Jayaprakashvel et al. (2010), a autoclavagem $\left(121^{\circ} \mathrm{C}\right.$ por 15 minutos $)$ de metabólito proveniente de um agente de biocontrole pode reduzir em $24 \%$ a sua atividade antifúngica quando comparada a não autoclavagem. Já Carvalho et al. (2007) postulam que moléculas bioativas, presentes em metabólitos de origem microbiana, podem se decompor em outras moléculas menos ativas ou mesmo inativas, quando submetidas a condições inadequadas que levem à degradação das moléculas. O fato de alguns desses metabólitos

Tabela 1. Efeito inibidor de metabólitos voláteis e não voláteis termoestáveis de Trichoderma harzianum sobre o crescimento de Cladosporium herbarum.

\begin{tabular}{|c|c|c|}
\hline \multirow{2}{*}{$\begin{array}{l}\text { Isolado de } \\
\text { T. harzianum }\end{array}$} & \multicolumn{2}{|c|}{$\begin{array}{l}\text { Crescimento (\%) de colônias de } C \text {. herbarum } \\
\text { sob o efeito de metabólitos de } T \text {. harzianum }{ }^{1}\end{array}$} \\
\hline & Metabólitos voláteis & $\begin{array}{l}\text { Metabólitos não } \\
\text { voláteis termoestáveis }\end{array}$ \\
\hline CEN287 & $67,28 \mathrm{bA}$ & 66,41 aA \\
\hline CEN288 & 41,48 aA & $62,97 \mathrm{aB}$ \\
\hline CEN289 & $93,35 \mathrm{cB}$ & 69,39 aA \\
\hline CEN290 & $77,15 \mathrm{cA}$ & 71,33 aA \\
\hline CEN316 & 88,03 cB & 59,86 aA \\
\hline Testemunha ${ }^{2}$ & $100 \mathrm{c}$ & $100 \mathrm{~b}$ \\
\hline $\begin{array}{l}\text { Coeficiente de } \\
\text { variação }(\%)\end{array}$ & 20,43 & 10,47 \\
\hline
\end{tabular}

${ }^{1}$ Valores seguidos pela mesma letra minúscula em cada coluna e mesma letra maiúscula em uma linha, não diferem estatisticamente, segundo o teste de Scott-Knott $(\mathrm{P} \leq 0,05)$; ${ }^{2}$ Metabólitos voláteis: sem adição de disco do antagonista na placa correspondente; Metabólitos não voláteis termoestáveis: adicionou-se $5 \mathrm{~mL}$ de $\mathrm{ADE}$ ao BDA fundente das placas. 
se mostrarem estáveis em várias temperaturas suportaria a idéia de que os mesmos possam se manter ativos frente a diferentes fatores, como insolação e temperaturas mais elevadas dos solos de diferentes regiões, conforme mencionado anteriormente. Importante salientar que trabalhos desta natureza vislumbram a perspectiva de síntese destes metabolitos secundários seletivos para determinados organismos, por serem vantajosos em relação a outras moléculas de natureza química, sob a ótica ambiental (JAYAPRAKASHVEL et al., 2010).

Finalmente, é válido salientar que produtos comerciais têm sido lançados para o controle, principalmente de patógenos habitantes do solo (GERALDINE et al., 2013). Entretanto, não existem, ainda no mercado, produtos a base de Trichoderma para o controle de $C$. herbarum em sementes em que pese o fato de já ter sido verificado antagonismo de Trichoderma spp. sobre Cladosporium sp. (CARVALHO et al., 2011; GUIMARÃES et al., 2014). Neste contexto, trabalhos na área devem atentar-se para o fato de que os agentes de controle biológico podem agir contra patógenos, usando um ou mais mecanismos, tais como competição e, principalmente a antibiose (DEMIRCI et al., 2011).

\section{Conclusões}

O crescimento dos cinco isolados de T. harzianum pode ser representado por um único modelo polinomial do segundo grau.

Após verificar que metabólitos voláteis e não voláteis termoestáveis de $T$. harzianum inibiram o crescimento de C. herbarum, conclui-se que estes isolados possuem potencial para controle do patógeno.

\section{Agradecimentos}

Os autores agradecem à Coordenação de Aperfeiçoamento de Pessoal de Nível Superior (CAPES) por uma bolsa de mestrado. A Fundação de Amparo a Pesquisa do Estado de Goiás (FAPEG) pelo suporte financeiro (Processo 201310267001026). À Embrapa Recursos Genéticos e Biotecnologia pelos isolados de Trichoderma harzianum (TRTM 02/2012) e a Universidade Estadual de Goiás (UEG) por uma bolsa de produtividade em pesquisa (PROBIP).

\section{Referências}

AGÜERO, L. E. M. et al. Inhibition of Aspergillus flavus growth and aflatoxin b1 production in stored maize grains exposed to volatile compounds of Trichoderma harzianum Rifai. Interciência, Caracas, v. 33, p. 219-222, 2008.

AHMAD, J. S.; BAKER, R. Rhizosphere competence of Trichoderma harzianum. Phytopathology, Saint Paul, v. 77, p. 182-189, 1987.

ALWATHNANI, H. A. et al. Evaluation of biological control potential of locally isolated antagonist fungi against Fusarium oxysporum under in vitro and pot conditions. African Journal of Microbiology Research, Nairobi, v. 6, p. 312-319, 2012. http://dx.doi.org/10.5897/ AJMR11.1367.
AULER, A. C. V. et al. Antagonismo de Trichoderma harzianum a Sclerotium rolfsii nas culturas do feijoeiro e soja. Revista Agro@ mbiente On-line, Boa Vista, v. 7, p. 359-365, 2013.

BAKER, K. F.; SNYDER, W. C. Ecology of soil-borne plant pathogens: prelude to biological control. Berkeley. University of California Press, 1965.

CARVALHO, D. D. C. et al. Rhizobacteria able to produce phytotoxic metabolites. Brazilian Journal of Microbiology, São Paulo, v. 38, p. 759-765, 2007. http://dx.doi.org/10.1590/S1517-83822007000400032.

CARVALHO, D. D. C. et al. Biocontrol of seed pathogens and growth promotion of common bean seedlings by Trichoderma harzianum. Pesquisa Agropecuária Brasileira, Brasília, v. 46, n. 8, p. 822-828, 2011. http://dx.doi.org/10.1590/S0100-204X2011000800006.

CARVALHO, D. D. C. et al. Biological control of Fusarium oxysporum f. sp. phaseoli by Trichoderma harzianum and its use for common bean seed treatment. Tropical Plant Pathology, New York, v. 39, p. 384-391, 2014. http://dx.doi.org/10.1590/S1982-56762014000500005.

CARVALHO, D. D. C. et al. Biological control of Fusarium wilt on common beans by in-furrow application of Trichoderma harzianum. Tropical Plant Pathology, New York, v. 40, p. 375-381, 2015. http://link.springer.com/article/10.1007\%2Fs40858-015-0057-1

CORREAA, B. O. et al. Influence of bean seed microbiolization on the transmission of Colletotrichum Lindemuthianum (Saac e Magn.). Revista Brasileira de Sementes, Londrina, v. 30, p. 156-163, 2008 http://dx.doi.org/10.1590/S0101-31222008000200019.

DE BOER, W. et al. Microbial community composition affects soil fungistasis. Applied and Environmental Microbiology, Washington, v. 69 , p. 835-844, 2003. http://dx.doi.org/10.1128/ AEM.69.2.835-844.2003.

DEMIRCI, E. et al. In vitro antagonistic activity of fungi isolated from sclerotia on potato tubers against Rhizoctonia solani. Turkish Journal of Biology, Ankara, v. 35, p. 457-462, 2011. http://dx.doi. org/10.3906/biy-1004-98

EL-HASAN, A. et al. Detection of viridiofungin A and other antifungal metabolites excreted by Trichoderma harzianum active against different plant pathogens. European Journal of Plant Pathology, Dordrecht, v. 124, p. 457-470, 2009. http://dx.doi.org/10.1007/ s10658-009-9433-3.

ELLIS, M. B. Dematiaceous hyphomycetes. Wallingford: CAB International, 1971. $608 \mathrm{p}$.

FERREIRA, D. F. Sisvar: a computer statistical analysis system. Ciência e Agrotecnologia, Lavras, v. 35, n. 6, p. 1039-1042, 2011. http://dx.doi.org/10.1590/S1413-70542011000600001.

GERALDINE, A. M. et al. Cell wall-degrading enzymes and parasitism of sclerotia are key factors on field biocontrol of white mold by Trichoderma spp. Biological Control, San Diego, v. 67, p. 308-316, 2013. http://dx.doi.org/10.1016/j.biocontrol.2013.09.013.

GUIMARÃES, G. R. et al. Supression of seed borne Cladosporium herbarum on common bean seed by Trichoderma harzianum and promotion of seedling development. Tropical Plant Pathology, New York, v. 39, p. 401-406, 2014. http://dx.doi.org/10.1590/ S1982-56762014000500007.

HAJIEGHRARI, B. et al. Biological potential of some Iranian Trichoderma isolates in the control of soil borne plant pathogenic fungi. African Journal of Biotechnology, v. 7, p. 967-972, 2008. http://dx.doi.org/10.5897/AJB07.709.

HARMAN, G. E. et al. Trichoderma species - opportunistic, avirulent plant symbionts. Nature Reviews Microbiology, London, v. 2, p. 43-56, 2004. http://dx.doi.org/10.1038/nrmicro797. 
JAYAPRAKASHVEL, M. et al. Control of sheath blight disease in rice by thermostable secondary metabolites of Trichothecium roseum MML003. European Journal of Plant Pathology, Dordrecht, v. 126, p. 229-239, 2010. http://dx.doi.org/10.1007/s10658-009-9535-y.

LOPES, F. A. C. et al. Biochemical and metabolic profiles of Trichoderma strains isolated from common bean crops in the Brazilian cerrado, and potential antagonism against Sclerotinia sclerotiorum. Fungal Biology, Oxford, v. 116, p. 815-824, 2012. http://dx.doi.org/10.1016/j.funbio.2012.04.015.

MACHADO, D. D. F. et al. Trichoderma no Brasil: o fungo e o bioagente. Revista de Ciências Agrárias, Belém, v. 35, p. 274-288, 2012.

MARINO, R. H.; MESQUITA, J. B. Micoflora de sementes de feijão comum (Phaseolusvulgaris L.). provenientes do Estado de
Sergipe. Revista Brasileira de Ciências Agrárias, Recife, v. 4, p. 252-256, 2009.

POMELLA, A. W. V.; RIBEIRO, R. T. S. Controle biológico com Trichoderma em grandes culturas - uma visão empresarial. In: BETTIOL, W.; MORANDI, M. A. B. (Ed.). Biocontrole de doenças de plantas: uso e perspectivas. Jaguariúna: Embrapa Meio Ambiente, 2009. p. 239-244.

WOO, S. L. et al. The molecular biology of the interactions between Trichoderma spp., phytopathogenic fungi, and plants. Phytopathology, Saint Paul, v. 96, p. 181-185, 2006. http://dx.doi.org/10.1094/ PHYTO-96-0181.

Recebido: 21 jul. 2015

Aprovado: 20 jun. 2016 